\title{
Efeito do Grupo Genético e da Heterose na Composição Física e nas Características Qualitativas da Carcaça e da Carne de Vacas de Descarte Terminadas em Confinamento
}

\author{
João Restle ${ }^{1}$, Cristian Faturi ${ }^{2}$, Régis Augusto Carvalho Bernardes ${ }^{3}$, Dari Celestino Alves Filho ${ }^{3}$, Luis \\ Fernando Glasenapp de Menezes ${ }^{4}$, Alexandre Nunes Motta de Souza ${ }^{5}$, Charles de Oliveira Carrilho ${ }^{4}$
}

\begin{abstract}
RESUMO - Foram estudadas as características qualitativas da carcaça e da carne e a composição física das carcaças de vacas de descarte terminadas em confinamento, pertencentes a dois sistemas de acasalamento, puras (Charolês e Nelore) e mestiças F 1 1/2 Charolês-Nelore e $1 / 2$ Nelore-Charolês. Os animais foram confinados por 80 dias, recebendo uma dieta contendo $10 \%$ de PB, composta por $65 \%$ de volumoso (silagem de sorgo) e $35 \%$ de concentrado, com base na matéria seca. Observou-se, na comparação entre animais puros, que vacas Charolês apresentaram carcaças com maiores porcentagens de músculo $(65,21$ contra $58,83 \%)$ e osso $(15,26$ contra $13,7 \%)$ que vacas Nelore, bem como maiores produções de músculo (166,58 contra 139,61 kg) e osso $(38,84$ contra $32,34 \mathrm{~kg})$, além de melhor coloração $(3,75$ contra 3,14$)$, maciez $(6,22$ contra 5,34$)$ e suculência da carne $(6,16$ contra 5,56$)$. As vacas Nelore, no entanto, apresentaram maior percentagem (27,95 contra 19,85\%) e produção total de gordura (66,7 contra 51,2 kg), assim como maior quebra durante o descongelamento da carne $(6,15$ contra 4,18\%). Na comparação entre os sistemas de acasalamento, observou-se que os animais mestiços apresentaram maiores porcentagem (26,74 contra $23,90 \%)$ e produção total de gordura $(72,79$ contra $58,95 \mathrm{~kg}$ ) e menor percentagem de músculo na carcaça $(59,59$ contra $62,02 \%$ ) que a média dos puros, resultando em valores de heterose de 11,$88 ; 23,48$; e $-3,92 \%$, respectivamente. As características qualitativas da carne não foram influenciadas pelo sistema de acasalamento.
\end{abstract}

Palavras-chave: Bos indicus, Bos taurus, composição física da carcaça, cruzamento, qualidade da carne

\section{Breed and Heterosis Effects on Carcass Physical Composition and Meat Qualitative Characteristics of Feedlot Finished Cull Cows}

\begin{abstract}
Carcass physical composition and meat qualitative characteristics of cull cows from two breeding systems, straightbreds (Charolais and Nellore) and crossbreds F 1 1/2 Charolais-Nellore and 1/2 Nellore-Charolais, were evaluated. The cows were feedlot finished during 80 days and fed with $65 \%$ roughage (sorghum silage) and $35 \%$ concentrate, in dry matter basis. Charolais cows showed carcass with higher muscle ( $65.2 \mathrm{vs} 58.8 \%)$ and bone (15.36 vs $13.7 \%)$ percentages, higher muscle (166.5 vs $139.61 \mathrm{~kg})$ and bone (38.84 vs $32.34 \mathrm{~kg}$ ) production than Nellore cows. Meat from Charolais cows also exhibited better color (3.75 vs 3.14$)$, tenderness (6.22 vs 5.34 ) and juiciness (6.16 vs 5.56). Nellore cows showed higher fat percentage ( 27.95 vs $19.85 \%)$, total fat production (66.7 vs 51.2 $\mathrm{kg}$ ) and higher meat thawing losses (6.15 vs 4.18\%). Crossbreds F1 females were superior to the straightbreds for fat percentage (26.74 vs $23.9 \%$ ), total fat production ( $72.79 \mathrm{vs} 58.95 \mathrm{~kg}$ ), however, showed lower muscle percentage in the carcass $(59.59 \mathrm{vs} 62.02 \%)$, being the heterosis values $11.88,23.48$ and $-3.92 \%$, respectively. Meat qualitative characteristics were not affected by the breeding system.
\end{abstract}

Key Words: Bos Indicus, Bos taurus, carcass physical composition, crossbreeding, meat quality

\section{Introdução}

Da carne bovina consumida no Brasil uma parcela elevada é oriunda de fêmeas de descarte. Segundo dados estatísticos do Anualpec (2001), a previsão de abate de fêmeas, na sua grande maioria representada por vacas de descarte, será em 2001, de $43,3 \%$ do total de bovinos abatidos. Embora seja elevada a participação de vacas na produção de carne, ainda são poucos os trabalhos de pesquisa, no nosso meio, que avaliaram as suas características qualitativas.

Em vacas Bos taurus e Bos indicus terminadas em condição de pasto nativo, Restle et al. (1990a) e Perobelli et al. (1994) verificaram que o grupo genético influenciou características qualitativas importantes da carne - maciez, palatabilidade, marmoreio, quebra na cocção e suculência da carne.

\footnotetext{
${ }^{1}$ Eng ${ }^{\circ}-$ Agro, PhD, Professor Titular do Departamento de Zootecnia da UFSM - Santa Maria, RS. Pesquisador CNPq. Email: jorestle@ccr.ufsm.br

2 Zootecnista, Aluno do curso de Pós-Graduação em Zootecnia da UFSM.

${ }^{3}$ MS, Professor Assistente do Departamento de Zootecnia da UFSM.

${ }^{4}$ Acadêmico do curso de Zootecnia da UFSM. Bolsista UFSM.

${ }^{5}$ Acadêmico do curso de Medicina Veterinária da UFSM. Bolsista IC - CNPq.
} 
Vacas de diferentes genótipos, incluindo Bos taurus, Bos indicus e suas cruzas, terminadas em pastagem cultivada com suplementação energética, mostraram diferenças significativas na composição dos tecidos da carcaça e nos aspectos qualitativos da carne (Restle et al., 2001). Vaz et al. (2001), em seu estudo sobre o efeito da idade e do nível de suplementação energética para vacas de descarte mantidas em pastagem cultivada, verificaram que o nível de suplementação não afetou as características da carne, porém idade da vaca afetou a composição física da carcaça e a maciez da carne. Por outro lado, em condições de confinamento, Feijó et al. (2000) constataram que o aumento no nível de concentrado na terminação de vacas de descarte melhorou a palatabilidade da carne.

Estudando as características quantitativas e qualitativas da carcaça e da carne de vacas de descarte terminadas em confinamento, Restle et al. (1990b) verificaram maiores porcentagens de osso e músculo na carcaça de vacas Charolês e maior porcentagem de gordura em vacas Hereford, porém não constataram diferenças significativas nas características qualitativas entre os dois grupos genéticos. Já Schnell et al. (1997) verificaram, entre vacas de descarte de raças leiteiras, mestiços Brahman, inglesas e continentais, terminadas em confinamento, diferenças significativas na maciez da carne.

Os efeitos da heterose sobre as características qualitativas da carne têm sido estudados, principalmente, em novilhos (Slanger et al., 1985; Marshall et al., 1987; Restle et al., 1995a; Vaz, 1999), nos quais se destaca o grande efeito que a heterose apresenta sobre o marmoreio da carne. No entanto, os estudos sobre os efeitos da heterose nas características qualitativas da carne em vacas de descarte são praticamente inexistentes na literatura.

O presente trabalho foi conduzido com os objetivos de estudar a composição física da carcaça e as características qualitativas da carne de vacas de descarte Charolês, Nelore, $1 / 2$ Charolês $1 / 2$ Nelore e $1 / 2$ Nelore $1 / 2$ Charolês, terminadas em confinamento, e medir a heterose resultante.

\section{Material e Métodos}

O experimento foi desenvolvido no Setor de Bovinocultura de Corte do Departamento de Zootecnia da Universidade Federal de Santa Maria, localizada no município de Santa Maria, Estado do Rio Grande do Sul.
Foram estudadas as características qualitativas da carcaça e da carne de vacas de descarte de dois sistemas de acasalamento (SA): de raças puras (PU) e cruzadas (CR), e de diferentes genótipos em cada SA, PU: Charolês versus Nelore e CR: 1/2 CharolêsNelore versus $1 / 2$ Nelore-Charolês.

Foram utilizadas 45 vacas de descarte adultas, sendo 17 vacas da raça Charolês, 10 Nelore, 8 1/2 Charolês-Nelore e 10 1 $1 / 2$ Nelore-Charolês, com idade média inicial de 6, 6, 6 e 7 anos e peso médio inicial de $379,345,405$ e $399 \mathrm{~kg}$, respectivamente. Os animais foram tomados ao acaso do rebanho experimental do Departamento de Zootecnia. Essas fêmeas foram produzidas em um sistema que utiliza a inseminação artificial (período de 45 dias) e a monta natural (período de 45 dias). Durante o período de inseminação, foi utilizado o sêmen de oito touros Charolês e Nelore e, para repasse, quatro touros Charolês e quatro Nelore. Os touros que geraram as vacas Charolês foram os mesmos que geraram as vacas $1 / 2$ Charolês-Nelore e os touros Nelore que geraram as vacas Nelore, os mesmos que geraram as vacas $1 / 2$ Nelore-Charolês. A terminação dos animais foi realizada em confinamento por um período fixo de 80 dias, subdivididos em quatro períodos de 20 dias. Nos 19 dias que antecederam o período experimental, os animais foram submetidos à adaptação ao meio ambiente do confinamento e à dieta alimentar. Os animais foram alimentados com uma dieta contendo $10,43 \%$ de proteína bruta e 2,34 Mcal de energia digestível/kg de MS. A dieta era composta por $65 \%$ de volumoso (silagem de sorgo) e $35 \%$ de concentrado, expresso na matéria seca.

Os animais foram alimentados ad libitum duas vezes ao dia, uma pela manhã e outra pela tarde. A oferta de alimento foi $5 \%$ superior ao consumo voluntário diário. Durante a terminação, os animais foram mantidos em um confinamento semicoberto, provido de baias coletivas, com cocho e bebedouro regulado por torneira bóia.

Durante o período experimental, os animais foram pesados no início e final do experimento após um jejum de 14 horas, onde o peso final representou o peso de abate dos animais, tomado ainda na Fazenda Experimental do Setor de Bovinocultura de Corte, sendo de 522,6; 462,0; 538,2; e 513,2 kg, respectivamente, para as vacas Charolês, Nelore, $1 / 2$ CharolêsNelore e $1 / 2$ Nelore-Charolês. Após, os animais foram transportados para um frigorífico comercial, onde foram submetidos a jejum por um período de 24 horas, 
procedendo-se ao abate logo após, obedecendo o fluxo normal do estabelecimento. Após o abate e o resfriamento das carcaças por 24 horas em câmara fria, a uma temperatura de $0^{\circ} \mathrm{C}$, foram realizadas as avaliações na carcaça. Na meia-carcaça direita foi realizado um corte entre a $12^{\mathrm{a}}$ e $13^{\mathrm{a}}$ costelas, com o objetivo de expor o músculo Longissimus dorsi, no qual foram realizadas as medidas subjetivas de cor e textura, seguindo uma escala de 5 pontos, em que $1=$ coloração escura e textura muito grosseira e $5=$ coloração vermelha brilhante e textura muito fina. No mesmo local também foi feita a avaliação do marmoreio, seguindo uma escala de 18 pontos, distribuídos na classificação correspondente à traços leve, pequeno, médio, moderado e abundante (Müller, 1987).

A estimativa dos percentuais de osso, músculo e gordura das carcaças foi realizada por meio da separação física da secção correspondente à $10^{\mathrm{a}}, 11^{\mathrm{a}}$ e $12^{\mathrm{a}}$ costelas da meia-carcaça direita, seguindo o método preconizado por Hankins e Howe (1946) e adaptado por Müller (1973). Os pesos totais de músculo, gordura e osso foram obtidos multiplicando-se o peso de carcaça fria pelos respectivos percentuais, obtidos conforme descrito acima.

Para a avaliação da maciez, palatabilidade, suculência e força de cizalhamento, foram seguidos os procedimentos sugeridos por Müller (1987). Na meia-carcaça direita, foi retirada uma amostra do músculo Longissimus dorsi compreendida entre a $10^{\mathrm{a}}$ e $12^{\mathrm{a}}$ costelas, que foi embalada em uma lâmina de plástico e papel pardo e imediatamente congelada a uma temperatura de $-18^{\circ} \mathrm{C}$, por 15 dias. Após este período, foram retirados dois bifes, de $2,5 \mathrm{~cm}$ de espessura, da porção craneal da amostra ainda congelada, e postos para descongelar em refrigerador doméstico, a $4{ }^{\circ} \mathrm{C}$ por 24 horas. Após descongelados, foram assados em forno a uma temperatura interna de $70^{\circ} \mathrm{C}$. Um dos bifes foi pesado quando congelado e após descongelamento, para cálculo da quebra no descongelamento, e após a cocção, para cálculo da quebra na cocção. O mesmo ainda serviu como amostra para a avaliação da força necessária ao cizalhamento das fibras musculares, por intermédio do aparelho Warner-Bratzler Shear, sendo utilizada uma média de seis leituras por bife. O outro foi destinado à avaliação da maciez, palatabilidade e suculência, por intermédio de um painel composto por quatro avaliadores treinados, os quais atribuíam valores de 1 a 9 para maciez, palatabilidade e suculência, em que 1 corresponde a uma carne extremamente dura, gosto extremamente desagradável e extremamente seca; 5 , a uma carne com maciez, palatabilidade e suculência médias; e 9, a uma carne extremamente macia, saborosa e suculenta.

O delineamento experimental utilizado foi o inteiramente casualisado, com número diferente de repetições. Foram realizadas as análises de variância através do programa SAS (1993), seguindo o seguinte modelo estatístico:

$$
\mathrm{Y}_{\mathrm{ijk}}=\mathrm{M}+\mathrm{SA}_{\mathrm{i}}+\mathrm{GG}_{\mathrm{j}}\left(\mathrm{SA}_{\mathrm{i}}\right)+\mathrm{I}_{\mathrm{k}}+\mathrm{E}_{\mathrm{ijk}}
$$

em que: $Y_{i j k}=$ variáveis dependentes; $\mathrm{M}=$ média de todas as observações; $\mathrm{SA}_{\mathrm{i}}=$ efeito do sistema de acasalamento de ordem i, sendo 1 (puras) e 2 (cruzadas); $\mathrm{GG}_{\mathrm{j}}\left(\mathrm{SA}_{\mathrm{i}}\right)=$ efeito do grupo genético de índice $\mathrm{j}$, sendo $\mathrm{j}=1$ (Charolês), 2 (Nelore), 3 ( $1 / 2$ CharolêsNelore) e 4 ( $1 / 2$ Nelore-Charolês), dentro do sistema de acasalamento $\mathrm{i} ; \mathrm{I}_{\mathrm{k}}=$ efeito da covariável idade da vaca; $\mathrm{E}_{\mathrm{ijk}}=$ efeito aleatório residual.

Foi calculada a heterose para cada característica, a partir das médias ajustadas, por intermédio da seguinte fórmula:

$\mathrm{H} \%=($ Média dos cruzados/Média dos definidos - 1$) \times 100$

\section{Resultados e Discussão}

Na Tabela 1 são apresentados os resultados médios referentes à composição física da carcaça, relação músculo:osso e relação porção comestível:osso. Conforme pode ser observado na Tabela 1 , houve diferença $(\mathrm{P}<0,05)$ entre animais puros e mestiços $\mathrm{F} 1$ para as porcentagens de músculo ( 62,02 contra $59,59 \%)$ e gordura $(23,9$ contra $26,74 \%)$, resultando em heterose de $-3,92$ e $11,88 \%$, respectivamente. Já para porcentagem de osso não houve diferença significativa entre os sistemas de acasalamento, resultando em uma heterose não-significativa de $-2,76 \%$. Estudando a heterose de animais dos mesmos grupos, porém de uma categoria diferente, novilhos de 24 meses, Restle et al. (1995b) e Vaz (1999) encontraram heterose não-significativa de 0,49 e $-0,15 \%$ para porcentagem de músculo, 0,93 e 3,33\% para porcentagem de gordura e -1,98 e -2,56 para porcentagem de osso. Marshall (1994) cita que a porcentagem de músculo na carcaça de novilhos é pouco afetada pela heterose, relatando um valor de $-0,6 \%$ como média dos resultados de sete trabalhos de pesquisa.

Em seu estudo, Vaz (1999) salienta que características expressas de forma percentual (como é expressa normalmente a participação de músculo, 
RESTLE et al.

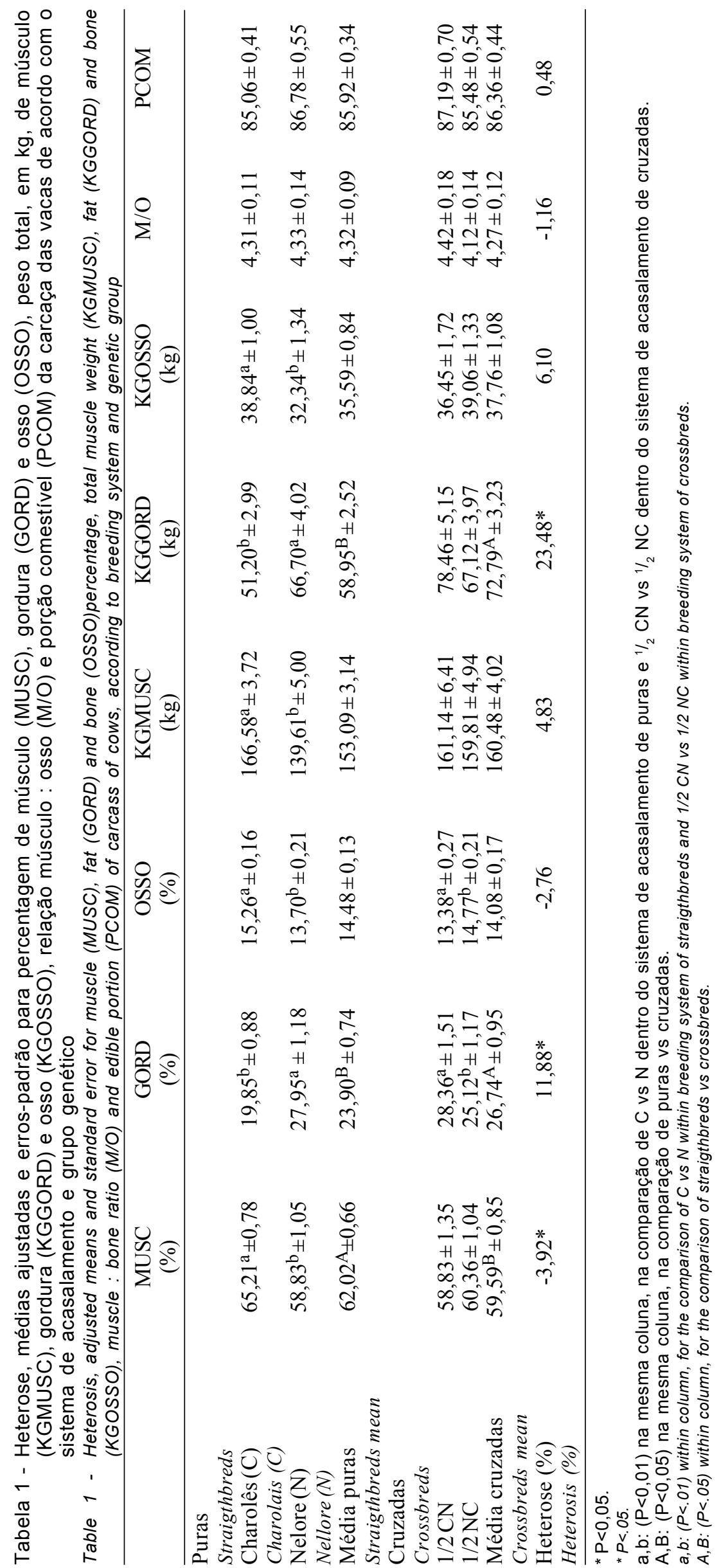


gordura e osso na carcaça), por serem medidas complementares, ou seja, a soma dos seus percentuais deve ser $100 \%$, não são as mais indicadas para expressar os valores de heterose, quando se deseja quantificar como estão se desenvolvendo os tecidos da carcaça de animais puros e mestiços. Nesse caso, o mesmo autor cita que a melhor maneira é expressar a composição da carcaça em peso total de músculo, gordura e osso.

$\mathrm{Na}$ Tabela 1 é apresentada a composição física da carcaça em peso total dos tecidos. Verifica-se que a quantidade total de músculo e osso dos animais mestiços F1 passaram a ser maiores do que nos animais puros em 4,83 e $6,1 \%$, respectivamente, porém a diferença não foi significativa. Já o peso total de gordura passou a ser $23,48 \%$ maior $(\mathrm{P}<0,05)$ nos animais $\mathrm{F} 1$. O maior peso dos tecidos nos animais $\mathrm{F} 1$ deve-se, em parte, ao maior peso de carcaça fria (269,8 contra 246,6 kg; Restle et al., 2002).

As porcentagens de heterose observadas seguiram a mesma tendência dos resultados relatados por Vaz \& Restle (2001), que encontraram em novilhos do mesmo rebanho heterose significativa de 11,5; 15,7; e 8,5\% para kg de músculo, gordura e osso, respectivamente. Estes autores observaram que, em novilhos, a heterose para $\mathrm{kg}$ de músculo e osso na carcaça foi significativa, principalmente pelo fato de que os animais F1 apresentaram desenvolvimento mais rápido até os 24 meses que a média dos puros $(11,6 \%)$. Já nas vacas de descarte a heterose para estas duas características deixou de ser significativa, em função da redução na diferença do peso de carcaça fria $(9,4 \%)$ e do aumento da quantidade de gordura na carcaça.

A porcentagem de gordura na carcaça, que foi $11,88 \%$ maior nas vacas $\mathrm{F} 1$, foi bem superior à heterose de 0,93 e 3,33\% relatada por Restle et al. (1995b) e Vaz (1999) para novilhos abatidos aos 24 meses. Já a quantidade de gordura expressa em $\mathrm{kg}$ apresentou heterose de $23,48 \%$, também superior aos $15,7 \%$ encontrados por Vaz e Restle (2001), em novilhos. A maior heterose para deposição de gordura nas vacas, animais mais velhos, indica que as mestiças, pelo fato de apresentarem crescimento mais rápido, atingiram o tamanho adulto mais cedo e, conseqüentemente, estavam depositando gordura a mais tempo.

Verifica-se que, na avaliação da composição física da carcaça, as características que apresentaram maior heterose foram a porcentagem de gordura e a quantidade de gordura em $\mathrm{kg}$ na carcaça. Esta constatação está de acordo com as observações de Slanger et al. (1985), Urick et al. (1989), Marshall (1994) e Vaz (1999), os quais relataram que as características relacionadas com a deposição de gordura são as que apresentam maior heterose. Segundo Gregory et al. (1994), a gordura é a característica que mais varia entre as raças bovinas de corte, e, de acordo com Köger (1980), quanto maior o distanciamento genético entre as raças, maior é o valor esperado de heterose. No presente trabalho, foram utilizadas duas raças com grande distanciamento genético, sendo uma raça européia tardia e uma raça zebuína com boa precocidade para deposição de gordura (Restle et al., 1990a; Restle et al., 1995b; Moletta \& Restle, 1996a; Vaz, 1999).

Comparando grupo genético dentro de sistema de acasalamento (Tabela 1), constata-se nos animais puros que as vacas Charolês foram superiores as Nelore em porcentagem de músculo $(65,2$ contra $58,83 \%$ ), peso de músculo (166,58 contra $139,61 \mathrm{~kg})$, percentagem de osso $(15,26$ contra $13,70 \%)$ e peso de osso na carcaça $(38,84$ contra $32,34 \mathrm{~kg})$. Já as vacas Nelore foram superiores em percentagem de gordura $(27,95$ contra $19,85 \%)$ e peso de gordura na carcaça $(66,70$ contra $51,20 \mathrm{~kg})$. As diferenças entre os grupos genéticos para os pesos absolutos dos componentes físicos devem-se, em parte, às diferenças do peso de carcaça.

A maior quantidade de músculo na carcaça das vacas Charolês é uma característica desta raça que foi desenvolvida com o objetivo de produzir alta proporção de carne na carcaça. A seleção do Charolês para a maior produção de carne resultou em maior proporção de osso na carcaça, já que este é a base para o desenvolvimento muscular. Conforme pode ser constatado na Tabela 4 , houve correlação positiva entre porcentagem de músculo e porcentagem de osso na carcaça $(\mathrm{r}=0,3721 ; \mathrm{P}=0,0118)$ e kg de músculo e $\mathrm{kg}$ de osso $(\mathrm{r}=0,6552 ; \mathrm{P}=0,0001)$.

No presente experimento, os animais foram sempre mantidos nas mesmas condições de manejo e alimentação e, após terem sido refugadas do rebanho de cria, foram confinadas durante um período fixo, sendo abatidos com idade média de 6 anos tanto as vacas Charolês como as Nelore. A composição física da carcaça certamente seria alterada, se o critério de abate fosse o peso, e também seria alterada, se o critério fosse o ponto de acabamento. Considerando que o peso mínimo exigido pelos frigoríficos é de $230 \mathrm{~kg}$ 
de carcaça e a gordura de cobertura mínima é de $3 \mathrm{~mm}$, se fosse adotado o critério de ponto de acabamento mínimo, as vacas Nelore não atingiriam o peso mínimo de carcaça, já que apresentaram peso de carcaça de 237,5 kg com 8,22 mm de gordura de cobertura, já acima do limite superior de $6 \mathrm{~mm}$. Se fosse adotado o critério de peso, as vacas Charolês provavelmente não atingiriam o grau de acabamento mínimo, uma vez que, com 255,8 kg de carcaça, a espessura de gordura foi de apenas 4,59 $\mathrm{mm}$ (Restle et al., 2002).

Maiores porcentagens de músculo e osso nas carcaças de vacas Charolês e maior porcentagem de gordura nas carcaças de vacas Nelore também foram relatadas por Restle et al.(1990a) e Perobelli etal. (1995), quando da terminação em condições de pastagem.

A composição percentual dos três tecidos observados para as vacas Charolês, no presente trabalho, foi similar à composição encontrada por Townsend et al. (1990) para vacas da mesma raça terminadas em confinamento. No entanto, Restle et al. (1990b) verificaram maior porcentagem de osso e menores porcentagens de músculo e gordura em vacas Charolês, quando comparado aos dados do presente experimento.

Entre as vacas mestiças, as $1 / 2$ Nelore-Charolês apresentaram maior porcentagem de osso, enquanto as $1 / 2$ Charolês-Nelore mostraram maior percentagem de gordura na carcaça (Tabela 1). Não houve diferença significativa entre os dois grupos para porcentagem de músculo, bem como para os três tecidos quando expressos em $\mathrm{kg}$.

A relação músculo:osso e a porção comestível da carcaça não foram afetadas significativamente pelo sistema de acasalamento nem pelo grupo genético (Tabela 1). Os valores para relação músculo:osso foram superiores aos citados por Perobelli et al. (1995) tanto para vacas Charolês $(3,50)$ como para vacas Nelore $(3,26)$. Vaz (1999) relatou heterose positiva e significativa de $2,92 \%$ para relação músculo:osso em novilhos abatidos aos dois anos, porém os valores para a relação foram inferiores aos do presente experimento, tanto para os animais Charolês e Nelore puros como para os mestiços F1.

$\mathrm{Na}$ Tabela 2 constam as médias para cor, textura e marmoreio da carne. Não houve diferença $(\mathrm{P}>0,05)$ para coloração da carne entre vacas puras e mestiças. Já entre as puras, as vacas Charolês apresentaram carne com melhor coloração, próxima ao vermelho (4), enquanto as vacas Nelore apresentaram coloração próxima ao vermelho levemente escuro (3). Entre os
Tabela 2 - Heterose, médias ajustadas e erros-padrão para cor (COR), textura (TEXT) e marmoreio (MARM) da carne das vacas, de acordo com o sistema de acasalamento e grupo genético

Table 2 - Heterosis, adjusted means and standard error for color (COR), texture (TEXT) and marbling (MARM) of meat of cows, according to the breeding system and genetic group

\begin{tabular}{|c|c|c|c|}
\hline & $\mathrm{COR}^{1}$ & TEXT $^{2}$ & MARM $^{3}$ \\
\hline \multicolumn{4}{|l|}{ Puras } \\
\hline \multicolumn{4}{|l|}{ Straigthbreds } \\
\hline Charolês (C) & $3,75^{\mathrm{a}} \pm 0,19$ & $2,90 \pm 0,25$ & $8,92 \pm 0,95$ \\
\hline \multicolumn{4}{|l|}{ Charolais $(C)$} \\
\hline Nelore (N) & $3,14^{\mathrm{b}} \pm 0,25$ & $2,51 \pm 0,33$ & $10,07 \pm 1,28$ \\
\hline \multicolumn{4}{|l|}{ Nellore (N) } \\
\hline Média puras & $3,45 \pm 0,16$ & $2,70 \pm 0,21$ & $9,50 \pm 0,80$ \\
\hline \multicolumn{4}{|c|}{ Straigthbreds mean } \\
\hline \multicolumn{4}{|l|}{ Cruzadas } \\
\hline \multicolumn{4}{|l|}{ Crossbreds } \\
\hline $1 / 2 \mathrm{CN}$ & $3,85 \pm 0,32$ & $2,84^{\mathrm{a}} \pm 0,43$ & $10,28 \pm 1,64$ \\
\hline $1 / 2 \mathrm{NC}$ & $3,36 \pm 0,25$ & $1,79^{b} \pm 0,33$ & $7,73 \pm 1,26$ \\
\hline Média cruzadas & $3,61 \pm 0,20$ & $2,31 \pm 0,27$ & $9,01 \pm 1,03$ \\
\hline \multicolumn{4}{|l|}{ Crossbreds mean } \\
\hline Heterose $(\%)$ & $-4,63$ & $-14,44$ & $-5,16$ \\
\hline Heterosis (\%) & & & \\
\hline
\end{tabular}

$a, b:(P<0,01)$ na mesma coluna, na comparação de $C$ vs $N$ dentro do sistema de acasalamento de puras e $1 / 2 \mathrm{CN}$ vs $1 / 2 \mathrm{NC}$ dentro do sistema de acasalamento de cruzadas $(a, b:[P<.01]$ within column, for the comparison of $C$ vs $N$ within breeding system of straigthbreds and $1 / 2 \mathrm{CN} v \mathrm{~s} 1 / 2 \mathrm{NC}$ within breeding system of crossbreds). $A, B:(P<0,05)$ na mesma coluna, na comparação de puras vs cruzadas $(A, B:[P<.05]$ within column, for the comparison of straigthbreds vs crossbreds).

1 Variação de 1 a 5 , sendo: $3=$ vermelho levemente escuro; $4=$ vermelho; $5=$ vermelho vivo $(3=$ slightly dark red; $4=$ red; $5=$ bright red $)$.

2 Variação de 1 a 5 , sendo: 1 = muito grosseira; 2 = grosseira;

$3=$ levemente grosseira $(1=$ very coarse; $2=$ coarse; $3=$ slightly coarse).

$37=$ pequena $-; 8=$ pequena $; 9=$ pequena $+; 10=$ média $(7=$ small -; 8 = small; $9=$ small $+; 10=$ medium).

animais mestiços, não houve diferença $(\mathrm{P}>0,05)$ na coloração da carne.

A coloração da carne é a primeira característica avaliada pelo consumidor no momento da compra. Carne vermelha escura, em geral, é rejeitada pelo consumidor, que associa, por intuição, a coloração escura com possível deterioração. Normalmente, vacas, por serem animais mais velhos, apresentam coloração mais escura que novilhos (Townsend et al., 1990), em função da maior concentração de mioglobina. Verificou-se, no presente experimento, que todos os grupos genéticos apresentaram coloração entre vermelho levemente escuro e vermelho, o que pode ser considerado satisfatório para esta categoria.

Coloração mais escura da carne de vacas Nelore em relação às Charolês também foi verificada por Perobelli et al. (1994). No entanto, Restle et al. 
(1990a) não verificaram diferença na coloração da carne de vacas de descarte destas duas raças, embora a coloração tenha sido inferior às encontradas no presente experimento.

A textura e o grau de marmorização da carne não foram afetados $(\mathrm{P}>0,05)$ pelo sistema de acasalamento (Tabela 2). Vacas mestiças filhas de touro Nelore apresentaram carne com textura entre muito grosseira e grosseira, pior $(\mathrm{P}>0,05)$ que das vacas filhas de touro Charolês classificada entre grosseira e levemente grosseira. Tendências similares foram citadas para novilhos dos mesmos grupos genéticos por Restle et al. (1995a) e Vaz (1999).

A textura da carne é avaliada subjetivamente pela granulação que a superfície do músculo apresenta quando é cortada, sendo constituída por um conjunto de fibras musculares agrupadas em fascículos envolvidos por uma camada de tecido conectivo, o perimisio. Conforme pode ser verificado na Tabela 4, a correlação entre textura e maciez da carne foi positiva $(\mathrm{r}=0,2983 ; \mathrm{P}=0,0466)$, indicando que carne com textura mais fina foi mais macia.
$\mathrm{Na}$ Tabela 3 constam as médias referentes às perdas de peso durante o descongelamento e cocção, à força de cizalhamento, maciez, palatabilidade e suculência da carne. A heterose para estas características não foi significativa $(\mathrm{P}>0,05)$, o que também foi constatado na carne de novilhos (Restle et al., 1995a; Vaz, 1999).

A carne das vacas Nelore perdeu mais líquidos durante o descongelamento e foi menos suculenta após a cocção, na avaliação dos degustadores. Vaz (1999), avaliando a carne de novilhos abatidos aos 24 meses, também constatou maiores perdas no peso da carne durante o descongelamento e menor suculência para os Nelore em relação aos Charolês. No entanto, Perobelli et al. (1994), estudando a qualidade da carne de vacas terminadas em condições de pastagem, não verificaram diferenças entre as Charolês e Nelore para as perdas durante o descongelamento, mas sim durante a cocção, que foram maiores para as últimas, o que afetou de maneira significativa a suculência da carne. Utilizando animais abatidos aos

Tabela 3 - Heterose, médias ajustadas e erros-padrão para perda no descongelamento (DESCON), perda na cocção (COCÇÃO), força de cizalhamento (SHEAR), maciez (MACIEZ), palatabilidade (PALAT) e suculência (SUCUL) da carne das vacas de acordo com o sistema de acasalamento e grupo genético

Table 3 - Heterosis, adjusted means and standard error for thawing losses (DESCON), cooking losses (COCÇÃO), shear force (SHEAR), tenderness (MACIEZ), palatability (PALAT) and juiciness (SUCUL) of meat of cows according breeding system and genetic group

\begin{tabular}{|c|c|c|c|c|c|c|}
\hline & $\begin{array}{c}\text { DESCON } \\
(\%)\end{array}$ & $\begin{array}{c}\text { COCÇÃO } \\
(\%)\end{array}$ & SHEAR $^{1}$ & MACIEZ $^{2}$ & PALAT $^{3}$ & SUCUL $^{4}$ \\
\hline \multicolumn{7}{|l|}{ Puras } \\
\hline \multicolumn{7}{|l|}{ Straigthbreds } \\
\hline Charolês (C) & $4,18^{\mathrm{b}} \pm 0,43$ & $26,80 \pm 0,76$ & $5,97 \pm 0,36$ & $6,22^{\mathrm{a}} \pm 0,24$ & $6,39 \pm 0,20$ & $6,16^{\mathrm{a}} \pm 0,20$ \\
\hline \multicolumn{7}{|l|}{ Charolais (C) } \\
\hline Nelore (N) & $6,15^{a} \pm 0,58$ & $25,84 \pm 1,02$ & $6,84 \pm 0,48$ & $5,34^{\mathrm{b}} \pm 0,32$ & $6,51 \pm 0,27$ & $5,56^{\mathrm{b}} \pm 0,27$ \\
\hline Nellore (N) & & & & & & \\
\hline Média puras & $5,17 \pm 0,36$ & $26,32 \pm 0,64$ & $6,40 \pm 0,30$ & $5,78 \pm 0,20$ & $6,45 \pm 0,17$ & $5,86 \pm 0,17$ \\
\hline \multicolumn{7}{|l|}{ Straigthbreds mean } \\
\hline \multicolumn{7}{|l|}{ Crossbreds } \\
\hline $1 / 2 \mathrm{CN}$ & $5,17 \pm 0,74$ & $26,41 \pm 1,31$ & $5,55 \pm 0,62$ & $6,10 \pm 0,41$ & $6,78^{a} \pm 0,34$ & $6,06 \pm 0,35$ \\
\hline $1 / 2 \mathrm{NC}$ & $5,38 \pm 0,57$ & $27,05 \pm 1,01$ & $6,44 \pm 0,48$ & $5,70 \pm 0,31$ & $6,05^{b} \pm 0,26$ & $5,78 \pm 0,27$ \\
\hline Média cruzadas & $5,28 \pm 0,46$ & $26,73 \pm 0,82$ & $6,00 \pm 0,39$ & $5,90 \pm 0,26$ & $6,41 \pm 0,22$ & $5,92 \pm 0,22$ \\
\hline \multicolumn{7}{|l|}{ Crossbreds mean } \\
\hline Heterose, $(\%)$ & 2,13 & 1,56 & $-6,25$ & 2,08 & $-0,62$ & 1,02 \\
\hline
\end{tabular}

Heterosis,

a,b: $(P<0,01)$ na mesma coluna, na comparação de $C$ vs $N$ dentro do sistema de acasalamento de puras e $1 / 2 \mathrm{CN}$ vs $1 / 2 \mathrm{NC}$ dentro do sistema de acasalamento de cruzadas $(a, b:[P<.01]$ within column, for the comparison of $C$ vs $N$ within breeding system of straigthbreds and $1 / 2 \mathrm{CN}$ vs $1 / 2$ NC within breeding system of crossbreds).

$A, B:(P<0,05)$ na mesma coluna, na comparação de puras vs cruzadas $(A, B:(P<.05)$ within column, for the comparison of straigthbreds vs crossbreds).

1 Maior valor $=$ carne mais dura (higher value $=$ tougher meat ).

2 Maciez ( 5 = maciez média; $6=$ maciez levemente acima da média; $7=$ macia) $($ Tenderness $[5=$ medium tenderness; $6=$ tenderness slightly above average; 7 = tender $]$.

3 Maior valor $=$ melhor palatabilidade (higher value $=$ better flavor).

4 Maior valor $=$ maior suculência (higher value $=$ higher juiciness).

\section{R. Bras. Zootec., v.31, n.3, p.1378-1387, 2002 (suplemento)}




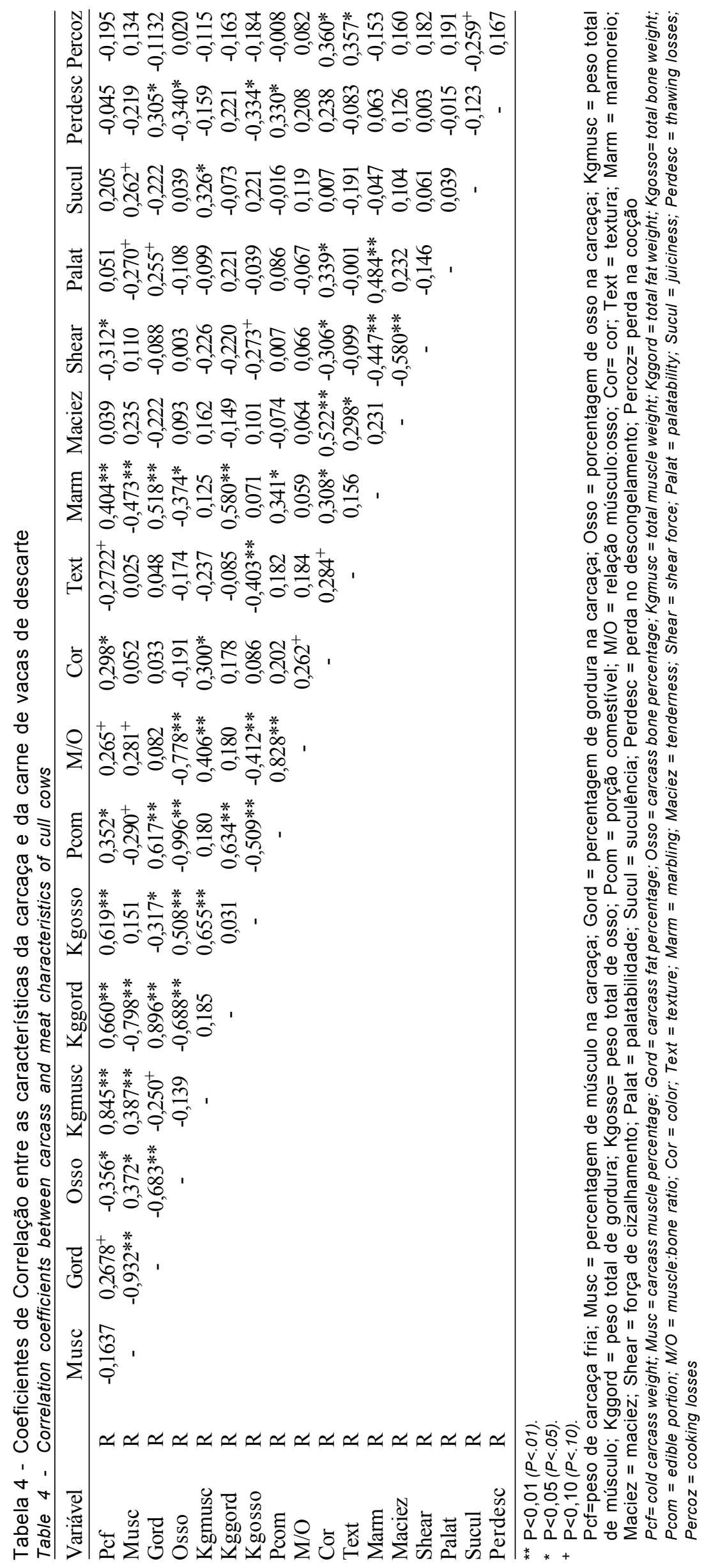


quatorze meses de idade, Flores (1997) e Restle et al. (1997) verificaram que, em novilhos mestiços Nelore $\mathrm{x}$ Hereford, o incremento de Nelore no genótipo aumentou a quebra ao descongelamento, fazendo com que a suculência da carne decrescesse. Sherbeck et al. (1995) também constataram que a suculência da carne decresceu, à medida que aumentou a porcentagem de Brahman no genótipo.

Com relação à maciez, que é o atributo qualitativo mais importante da carne, verifica-se que esta foi melhor nas vacas Charolês. A melhor maciez da carne das raças européias em relação às zebuínas está amplamente citada na literatura estrangeira (Crouse et al., 1989; Johnston et al., 1992; Wheeler et al., 1990; Whipple et al., 1990; Marshall et al., 1994) e na literatura brasileira (Restle et al., 1990a; Perobelli et al., 1994; Moletta e Restle, 1996b; Restle et al., 1995a; Flores, 1997; Restle et al., 1999; Vaz, 1999).

A carne dos zebuínos apresenta, na sua estrutura, maior concentração de calpastatina, que tem efeito inibidor sobre as enzimas proteolíticas do grupo calpaína (Wheeler et al., 1990; Whipple et al., 1990) contribuindo para a menor maciez da carne dos zebuínos.

Crouse et al. (1989) relataram que a menor maciez da carne de animais zebuínos em relação aos europeus deve-se ao fato de ocorrer menor fragmentação da miofibrila e existir maior percentual de tecido conectivo na carne magra desses animais. Restle et al. (1997) verificaram, em machos abatidos aos quatorze meses, maior maciez na carne não maturada para os Hereford do que para os $5 / 8$ Hereford 3/8 Nelore, sendo que os teores de colágeno por grama de músculo foram de 3,70 e $3,91 \mathrm{mg}$, respectivamente.

O painel de avaliadores classificou a carne das vacas Charolês e 1/2 Charolês-Nelore acima de 6 (carne com maciez levemente acima da média) e das vacas Nelore e 1/2 Nelore-Charolês acima de 5 (carne com maciez média).

Embora a força de cizalhamento tenha sido maior na carne dos Nelore, a diferença não chegou a ser significativa (Tabela 3 ). Os valores médios encontrados para vacas puras e mestiças foram 6,4 e 6,0, respectivamente. Vacas $1 / 2$ Charolês-Nelore apresentaram carne mais palatável do que vacas $1 / 2$ Nelore-Charolês. A melhor palatabilidade das primeiras provavelmente deve-se à maior quantidade de gordura intramuscular (marmorização). Na Tabela 4, pode-se verificar que o coeficiente de correlação entre a quantidade de gordura intramuscular e palatabilidade foi de $0,4836(\mathrm{P}=0,0008)$, indicando que carnes com maior quantidade de gordura foram mais saborosas. Perobelli et al. (1994) também atribuíram a melhor palatabilidade da carne em vacas ao maior grau de marmorização.

\section{Conclusões}

Vacas Charolês apresentaram carcaças com maior porcentagem de músculo e de osso que vacas Nelore, como também maior peso total destes tecidos.

Vacas Nelore apresentaram carcaças com maior porcentagem e peso total de gordura que vacas Charolês.

Vacas Charolês apresentaram carne mais macia e suculenta, bem como melhor coloração que a carne de vacas Nelore, sendo que a carne destas apresentou maior perda durante o descongelamento.

Na comparação entre sistemas de acasalamento, as carcaças das fêmeas mestiças foram superiores à média das puras quanto à porcentagem e peso total de gordura, porém apresentaram menor porcentagem de músculo.

\section{Literatura Citada}

ANUALPEC. Anuário da pecuária brasileira. São Paulo: Oesp Gráfica SA., 2001. 359p.

CROUSE, J.D.; CUNDIFF, L.V.; KOCH, R.M. et al. Comparisons of Bos Indicus and Bos Taurus inheritance for carcass beef characteristics and meat palatability. Journal of Animal Science, v.67, n.10, p.2661-2668, 1989.

FEIJÓ, G.L.; SILVA, J.M.; LOPES, L.R. et al. 2000. Produção e qualidade da carne de vacas de descarte. Características das carcaças de vacas em confinamento sob diferentes níveis de concentrado. In: REUNIÃO ANUAL DA SOCIEDADE BRASILEIRA DE ZOOTECNIA, 37., 2000, Viçosa, MG Anais...Viçosa: Sociedade Brasileira de Zootecnia/Gnosis, [2000]. CD-ROOM. Nutrição de ruminantes. 0820.

FLORES, J.L.C. Desempenho em confinamento e características de carcaça e da carne de bovinos de diferentes grupos genéticos abatidos aos quatorze meses. Santa Maria: Universidade Federal de Santa Maria, 1997. 109p. Dissertação (Mestrado em Zootecnia) - Universidade Federal de Santa Maria, 1997.

GREGORY, K.E.; CUNDIFF, L.V.; KOCH, R.M. et al. Breed effects, retained heterosis, and estimated of genetic and phenotypic parameters for carcass and meat traits of beef cattle. Journal of Animal Science, v.72, n.5, p.1174-1183, 1994.

HANKINS, O.G.; HOWE, P.E. Estimation of th composition of beef carcasses and cuts. Technical Bulletin, n.926, 1946. 21 p.

JOHNSTON, D.J.; THOMPSON, J.M.; HAMMOND, K. Additive and nonadditive differences in post weaning growth and carcass characteristics of Devon, Hereford and reciprocal cross steers. Journal of Animal Science, v.70, n.9 p.2688-2694, 1992. 
KOGER, M. Effective crossbreding systems utilizing zebu cattle. Journal of Animal Science, v.50, n.6, p.1213-1220, 1980.

MARSHALL, T.T.; HARGROVE, D.D.; OLSON, T.A. Heterosis and additive breed effects on feedlot and carcass traits from crossing Angus and Brown Swiss. Journal of Animal Science, v.64, n.5, p.1332-1339, 1987.

MARSHALL, D.M. Breed differences and genetic parameters for body composition traits in beef cattle. Journal of Animal Science, v.72, n.10, p.2745-2755, 1994.

MOLETTA, J.L.; RESTLE, J. Características de carcaça de novilhos de diferentes grupos genéticos terminados em confinamento. Revista Brasileira de Zootecnia, v.26, n.5, p.876-888, 1996a.

MOLETTA, J.L.; RESTLE, J. Influência do grupo genético sobre características qualitativas da carne de novilhos. Revista Brasileira de Zootecnia, v.26, n.5, p.866-875, 1996b.

MÜLLER, L. Normas para avaliação de carcaças e concurso de carcaça de novilhos. 2.ed. Santa Maria: Universidade Federal de Santa Maria, 1987. 31p.

MÜLLER, L. Técnicas para determinar la composición de la canal. Memoria de la Assocciación Latinoamericana de Producción Animal. Guadalajara: 1973. p.75.

PEROBELLI, Z.V.; MÜLLER, L.; RESTLE, J. Estudo da qualidade das carcaças e da carne de vacas de descarte de dois grupos genéticos. Ciência Rural, v.24, n.3, p.613-616, 1994.

PEROBELLI, Z.V.; RESTLE, J.; MÜLLER, L. Estudo das carcaças de vacas de descarte das raças Charolês e Nelore. Pesquisa Agropecuária Brasileira, v.30, n.3, p.409-412, 1995.

RESTLE, J.; MÜLLER, L.; GRASSI, C. et al. Características quantitativas das carcaças de vacas de descarte das raças Charolês e Nelore. In: REUNIÃO ANUAL DA SOCIEDADE BRASILEIRA DE ZOOTECNIA, 27., 1990, Campinas. Anais...Campinas: Sociedade Brasileira de Zootecnia, 1990a. p.349.

RESTLE, J.; SILVA, L.C.R.; MÜLLER, L. et al. Características de carcaça e da carne de vacas Hereford e Charolês terminadas em regime de confinamento. In: REUNIÃO ANUAL DA SOCIEDADE BRASILEIRA DE ZOOTECNIA, 27., 1990, Campinas. Anais...Campinas: Sociedade Brasileira de Zootecnia, 1990b. p.353.

RESTLE, J.; FELTEN, H.G.; VAZ, F.N.; MÜLLER, L. Efeito da raça e heterose para qualidade da carcaça e da carne de novilhos terminados em confinamento. In: REUNIÓN LATINOAMERICANA DE PRODUCCIÓN ANIMAL, 14., 1995, Mar del Plata. Memorias... Balcare: Assocciación Latinoamericana de Producción Animal, 1995a. n.3-4, p.854-856.

RESTLE, J.; FELTEN, H.G.; VAZ, F.N. Efeito da raça e heterose para características quantitativas da carcaça de novilhos de 24 meses terminados em confinamento. In: REUNIÓN LATINOAMERICANA DE PRODUCCIÓN ANIMAL, 14., 1995, Mar del Plata. Memorias...Balcare: Assocciación Latinoamericana de Producción Animal, 1995b. n.3-4, p. 857-859.

RESTLE, J.; ROCHA, J.B.T.; FLORES, J.L.C. et al. Qualidade da carne de animais Hereford e suas cruzas com Nelore, abatidos aos quatorze meses. In: REUNIÃO ANUAL DA SOCIEDADE BRASILEIRA DE ZOOTECNIA, 34., 1997, Juiz de Fora. Anais...Juiz de Fora: Sociedade Brasileira de Zootecnia, 1997, p.196-198.

RESTLE, J.; VAZ, F.N.; QUADROS, A.R.B. et al. Características de carcaça e da carne de novilhos de diferentes genótipos de Hereford x Nelore. Revista Brasileira de Zootecnia, v.28, n.6, p.1245-1251, 1999.

RESTLE, J.; VAZ, F.N.; ROSO, C. et al. Desempenho e características de carcaça de vacas de diferentes grupos genéticos, submetidas a níveis de suplementação energética em pastagem cultivada de estação fria. Revista Brasileira de Zootecnia, v.30, n.6., p.1813-1823, 2001.

R. Bras. Zootec., v.31, n.3, p.1378-1387, 2002 (suplemento)
RESTLE, J.; PASCOAL, L.L.; FATURI, C. et al. Efeito do grupo genético e da heterose nas características quantitativas da carcaça de vacas de descarte terminadas em confinamento. Revista Brasileira de Zootecnia, v.31, n.1, p.350-362, 2002. (suplemento)

SAS INSTITUTE.SAS/STAT User's guide: statistics. 4.ed. v.2. Version 6. Cary: 1993. 943p.

SCHNELL, T.D.; BELK, K.E.; TATUM, J.D. et al. Performance, carcass and palatability traits for cull cows fed high-energy concentrate diets for $0,14,28,42$, or 56 days. Journal of Animal Science, v.75, n.5, p.1195-1202, 1997.

SHERBECK, J.A.; TATUM, J.D.; FIELD, T.G. et al. Feedlot performance, carcass traits, and palatability traits of Hereford and Hereford Brahman steers. Journal of Animal Science, v.73, n.12, p.3613-3620, 1995.

SLANGER, W.D.; MARCHELLO, M.J.; DANIELSON, R.B. et al. Muscle tenderness, other carcass traits and the effect of crossbreding on theses traits in beef cattle. Journal of Animal Science, v.61, n.6, p.1402-1410, 1985.

TOWNSEND, M.; RESTLE, J.; PASCOAL, L.L. et al. Características qualitativas das carcaças de novilhos e vacas terminadas em confinamento. In: REUNIÃO ANUAL DA SOCIEDADE BRASILEIRA DE ZOOTECNIA, 27., 1990, Campinas. Anais...Campinas: Sociedade Brasileira de Zootecnia, 1990. p.361.

URICK, J.J.; PAHNISH, O.F.; KNAPP, B.W. et al. Comparison of two- and three-way rotational crossing, beef $x$ beef and beef $\mathrm{x}$ brown swiss composite breed production: postweaning growth and carcass traits. Journal of Animal Science, v.67, n. 10, p.2603-2618, 1989.

VAZ, F.N. Cruzamento alternado das raças Charolês e Nelore: características de carcaça e da carne de novilhos abatidos aos dois anos. Santa Maria: Universidade Federal de Santa Maria, 1999. 58p. Dissertação (Mestrado em Zootecnia) Universidade Federal de Santa Maria, 1999.

VAZ, F.N.; RESTLE, J. Efeito de raça e heterose para características de carcaça de novilhos da primeira geração de cruzamento entre Charolês e Nelore. Revista Brasileira de Zootecnia, v.30, n.2, p.409-416, 2001.

VAZ, F.N.; RESTLE, J.; BERNARDES, R.A.C. et al. Efeito da idade ao abate sobre a qualidade da carcaça e da carne de vacas Charolês, terminadas com suplementação em pastagem cultivada de estação fria. In: REUNIÃO ANUAL DA SOCIEDADE BRASILEIRA DE ZOOTECNIA, 38., 2001, Piracicaba. Anais... Piracicaba: Sociedade Brasileira de Zootecnia, 2001. p.1535-1537.

WHEELER, T.L.; SAVELL, J.W.; CROSS, H.R. et al. Mechanisms associated with the variation in tenderness of meat from Brahman and Hereford cattle. Journal of Animal Science, v.68, n.12, p.4206-4220, 1990.

WHIPPLE, G.; KOOHMARAIE, M.; DIKEMAN, M.E. et al. Evaluation of atributes that affect longissimus muscle tenderness in Bos taurus and Bos indicus cattle. Journal of Animal Science, v.68, n.9, p.2716-2728, 1990.
Recebido em: 05/10/01 Aceito em: 15/03/02 